\title{
Effects of Workload Job Demand and Ineffective Leadership on Offshore Employee Well-being in Oil and Gas Industry: The Mediating Role of Friend Support
}

\author{
M Wazien Afifi Abdul Wahab ${ }^{1}$, Imelda Albert Gisip ${ }^{1 *}$, Sharifah Nurafizah Syed \\ Annuar ${ }^{1}$
}

${ }^{1}$ Universiti Teknologi MARA (UiTM), Sabah, MALAYSIA

*Corresponding Author

DOI: https://doi.org/10.30880/jstard.2021.03.01.009

Received 3 March 2021; Accepted 16 May 2021; Available online 15 June 2021

\begin{abstract}
The aim of this study is to examine effects of workload job demand and ineffective leadership to the offshore employee well-being in oil and gas industry. In addition, this study also seeks to determine the mediating role of friend support to the relationships of workload job demand and ineffective leadership with offshore employee well-being. This paper is mainly based on secondary sources of information, through references and review of articles in selected journals pertaining to workload job demand, ineffective leadership and employee well-being in oil and gas industry. This paper highlights past studies on the effects of workload job demand and ineffective leadership to the offshore employee well-being. The reviews also address the related gaps from previous studies. This research paper is based on original research which seeks to contribute new knowledge and new approaches to solving existing problems by adapting and testing the mediating effects of friend support to the relationships between workload job demand and ineffective leadership with employee well-being particularly in the oil and gas industry.
\end{abstract}

Keywords: Work job demand, ineffective leadership, employee well-being, oil and gas industry, offshore, friend support

\section{Introduction}

Offshore working environment is generally considered as extreme, isolated and remote where psychological challenges are reportedly experienced even among physically healthy individuals (Mika et al., 2012). The leading global energy digital and news platform, Energy Voice also reported that these workers on average tend to spend several weeks away from home at any one time, doing demanding shift work in an often-harsh environment (Taylor, 2018). Smaller workforces and reduced manpower imply high workload and demands, while the downturn in the oil industry has also hindered career prospects and created job uncertainty. Based on the report published by Ernst \& Young LLP Transaction Services on December 2016, since the oil price nosedive began in June 2014, the Oil \& Gas industry has experienced a downturn that has endured for more than two years.

In working environment, employee considered to be the most valuable asset to the organization. Their dissatisfaction with their work and life will affect their commitment and dedication toward their job, family and organization. The employee perceives their surroundings be it from work or non-work related has influence on their well-being. In fact, employee well-being serves as one of the important key elements in sustaining a business or a company in a long run (Craig \& Kuykendall, 2019; Nauman, Raja, Haq \& Bilal 2019).

The topic on employee well-being was mostly discussed in a working environment which require high commitment to the job given. Workload job demand to be completed led an employee into stress mode that affect their well-being. Besides, a decrease in employee well-being resulted to the poor job performance. In addition, workload job demand also drives the employee into mental exhaustion as they have to deal with the amount of stress from the heavy work commitment (Bakker, Demerouti, De Boer \& Schaufeli, 2003). Considering this scenario in a working environment, a 
wise leadership should be able to control the imbalance between employee and job demand by creating a healthy working environment.

Apart from workload job demand, an employee also has to deal with an ineffective leadership though it is not happening in every organization (Pyc, Meltzer, \& Liu, 2016). Ineffective leadership may happen in an organization when the leader itself refuse to understand the struggle faced by his/her subordinate (Yukl, 2012). Some may have to deal with an abusive leader which always linked to the workplace bullying be it in the form of hostile verbal communication or non-verbal action (i.e. being rude and shows no respect to the co-worker). While some employees have to deal with a leader with full authority. They show no empathy to the employee as long as the work completed within the time frame. Continuous inappropriate action from ineffective leadership may contribute to the increase of stress among co-worker.

In the literature, there is an increase numbers of research done related to the employee well-being in the recent years (Craig \& Kuykendall, 2019; Nauman, Raja, Haq \& Bilal 2019). Most studies focusing on the possible variables that may led to the disruption of the employee well-being. Nonetheless, there has been very minimal or less research to investigate the perception of employee towards workload job demand and ineffective leadership and whether this perception will have a heavy impact and influence on the employee well-being in the industry (Ahmad, Sohal \& Cox, 2019). Therefore, this study aims to fill this gap by examining effects of workload job demand and ineffective leadership to the offshore employee well-being in oil and gas industry.

Apart from the abovementioned issues, healthy working environment matters have also been widely debated (Nguyen \& Dinh, 2019). It is the leader's responsibility to provide healthy working environment while keep checking up his/her subordinates' well-being. When the leader refuses to provide the basic requirement for the employee wellbeing, then it gives no other choice for the employee to find comfort to release their exhaustion. Family support indeed provide the best comfort; however, there are some that tend not to depend on family but turn to a friend instead (Craig \& Kuykendall, 2019). Hence, this study will also seek to investigate the mediating role of friend support to the relationship of workload job demand and ineffective leadership with the offshore employee well-being in oil and gas industry.

Overall, in addressing these gaps, workload job demand and the two dimensions of ineffective leadership style consisting of abusive supervision and authoritarian leadership style (ALS) are proposed as independent variables and friend support is introduced as moderating variables. The dependent variable in this study is employee well-being which is defined as emotional exhaustion and job satisfaction. The effect of the relationship of the independent variables to the dependent variable will be measured using primary and secondary data.

\section{Literature Review}

\subsection{Workload Job Demand}

Job demand refers to any kind of social, physical, psychological or organizational aspect of a certain task which requires continuous physical and mental effort (Bakker et al, 2003). Workload job demand refers to the overload limit of a certain task a person can handle. An employee requires double the physical and mental effort when given with workload quantity of task.

\subsection{Ineffective Leadership}

Ineffective leadership refers to the inability of a leader to manage his/her team or company in the right direction. There are many examples of ineffective leadership which in turn transform his/her team or company into total failure. the two types of ineffective leadership which further discussed in this study are the abusive supervision and authoritarian leadership style (ALS).

According to Tepper (2000), abusive supervision is the use of inappropriate verbal and nonverbal behavior toward the co-worker. An abusive supervisor tends to use vulgar words or action (i.e. inappropriate punishment) towards his/her coworker. The subordinate who became the victim of the abusive supervisor resulted to the decrease in his/her psychological and physical well-being.

Authoritarian leadership style (ALS) refers to the assertive, inflexible, overrule type of management style (Pyc, Meltzer, \& Liu, 2016). Under the management of ALS, the leader shows no inflexibility in term of work related. The employee forced to follow the rule set up by the ALS leader. In addition, co-worker also have to bear the pressure of working under the ALS leader as the leader actively shows his/her full authority towards the management or company which eventually can negatively impact the employee well-being.

\subsection{Employee Well-Being}

Employee well-being is not only focus on the psychological and mental healthiness of an employee but also focus on the healthiness of their physical (Ahmad, Sohal \& Cox, 2020). Ability to set purpose or target also consider the employee well-being as they have the sense of fulfilling in a team or company. Possessing an active mind also included in the aspect of employee well-being. Having a healthy relationship that are supportive also part of employee well-being. Being happy to be in the team or organization also show the positive employee well-being as they feel more motivated 
to work and this contribution may give benefit to the team or organization. It is a crucial moment to consider every positive aspect which can lead to a healthy well-being among employee as employee well-being is one of the key factors in realizing the team or company long term existence or competitiveness in the market (Craig \& Kuykendall, 2019).

\subsection{The Relationship between Workload Job Demand and Employee Well-Being}

Past studies proved that a high commitment in job demands can led to disruption of the employee well-being. These arguments were heavily discussed in paper published by Nauman, Raja, Haq, \& Bilal (2019) on "Job demand and employee wellbeing: A moderated mediation model of emotional intelligence and surface acting". The authors explained that workload job demands affects the employee's psychological healthiness even at the professional level. Workload job demands in a working environment can turn to burnout as they cannot handle the pressure, which drive the employee to feel emotional exhaustion and decrease in job satisfaction. The result was consistent with the discussion by Karasek (1979) on "Job demands, job decision latitude, and mental strain: Implications for job redesign" which revealed that heavy job commitment can harmful the employee's mental healthiness. In addition, according to the COR theory introduced by Hobfoll (1988), when an employee commit in job demand and cannot meet the requirement, job demand may turn into a stressor, which resulted to the emotional exhaustion and job satisfaction. Therefore, based on the point discussed, it is hypothesized that;

Hypothesis 1: There is a positive relationship between workload job demand and employee well being

\subsection{The Relationship between Ineffective Leadership and Employee Well-Being}

Ineffective leadership such as abusive leadership and authoritarian leadership style (ALS) found to be related to the employee well-being (Pyc, Meltzer, \& Liu 2016). The authors highlighted that an abusive leadership put much pressure than it seems on the employee. An abusive leader shows an arrogant personality and use vulgar words or being rude to the employee. They show no empathy to the employee when it comes to the job related. Working under the unhealthy environment which reduce the spirit of an employee to work has led to the decrease in employee well-being. Meanwhile, authoritarian leadership style (ALS) tends to put pressure on the employee (i.e. controlling the employee) to show their power. The employee was then forced to complete task(s) within the given time which put the employee into stress mode. This situation led to the exhaustion be it in time pressure, physical and emotional as well as resulted in job (dis)satisfaction. Considering the point discussed, it is hypothesized that;

Hypothesis 2: There is a positive relationship between Ineffective Leadership and Employee Well-Being Hypothesis 2a: There is a positive relationship between Abusive Supervision and Employee Well-Being Hypothesis 2b: There is a positive relationship between Authoritarian Leadership Style (ALS) and Employee Well-Being

\subsection{Friend Support}

Friendship is a typical relationship of mutual trust and support from a friend; it is a state of being a friend with whom you comfortable with, whereas friend support can be explained as a form of moral comfort being shared between friends (Craig \& Kuykendall, 2019). In a working environment, friend support may come from the work and non-work-related friend. Though family and spouse or romantic partner may share these attribute of offering comfort in term of moral support, it is theoretically distinct and feel different when it comes from a friend as friendship was more on freely choice to stay or leave while the commitment one have to focus on family and marriage relationship involve difficult step to abandoned (Hartup \& Stevens, 1997). With reference to the Social Support Resource Theory (SSRT) which is also based on COR theory, it is explained that friend support (social support) is important for the well-being as it boost the positive effect on one's self-esteem.

\subsection{The Relationship between Friend Support and Employee Well-Being}

It is dream for every employee to maintain a good life-balanced between work and family relationship. However, both roles required high commitment and not every employee can lead both roles in a good track. Exhausted working environment as well as family responsibilities can led an employee to dead end which may resulted to the absenteeism and poor performance as for the former, while the latter led to marital problem and abuse (Spector \& Jex, 1998). Moreover, this scenario was common if the employee failed to keep good track between work and family commitment. All this problem can affect the status of the employee well-being. Craig et al. (2019) have emphasized the importance of friendship contribution to employee's well-being. Pressure in working environment may lead employee to turn for someone for a comfort. A family without a doubt will give comfort but the pressure may be replaced by a family problem instead which the next supportive company an employee can turn to were from their friend. Past findings have further support friend as related to the employee well-being and also friendship is one of the important life-role in an employee 
(adulthood) daily as it is essential to maintain the well-being (McCarthy, Almeida, Ahrens, 2011). Thus, we hypothesize the following;

Hypothesis 3: There is positive relationship between friend support and employee well-being

\subsection{The Mediating Effect of Friend Support to the Relationship between Workload Job Demand and Employee Well-Being}

The relationship has limited reference as the study conducted on the topic is still few. However, according to Nauman, Raja, Haq, \& Bilal (2019), explained by giving a situation whereas a firefighter who work in odd hours and under unpredictable working circumstances also face a moment of exhaustion where they need social support to continue working. Through the social support, they felt more energetic to work diligently. Considering the situation, we thus hypothesize the following;

Hypothesis 4: Friend support mediates the relationship between workload job demand and employee well-being

\subsection{The Mediating Effect of Friend Support to the Relationship between Ineffective Leadership and Employee Well-Being}

The relationship is still relatively new and limited resources found to support the proposed hypothesis. However, by taking into account the explanation by Ahmad, Sohal, \& Cox (2019) who suggested that workplace bullying which happen because of an ineffective leadership has put much stress on the mental healthiness of an employee. It requires friend of work-related to talk face to face with the victim to offer their comfort. Therefore, based on the situation; thus, hypothesize the following;

Hypothesis 5: Friend support mediates the relationship between ineffective leadership and employee well-being

\subsection{Proposed Conceptual Framework}

\subsection{Underlying Theory}

The underlying theory in this study is based on Conservation of Resources (COR) Theory. The theory consists of four main principles as follows:

i. $\quad$ Resource loss: Experiencing a loss first in order to gain a new one.

ii. Resources investment:Natural tendency to protect from resources loss.

iii. Resource gain:Significance of resource gains in a resource loss situation.

iv. Desperation: Defensive mode or attempt to save the remaining resources because resource loss resulted in stress. The application of COR theory is used in the framework development to link the relationship between propose independent and dependent variable in this study, thus the research framework developed as shown in Figure 1. According to COR theory, when an employee commit in job demand and cannot meet the requirement, job demand may turn into a stressor; which resulted to the emotional exhaustion and job satisfaction. It is the same situation when apply to the ineffective leadership as the stressor. COR theory suggests that when an employee experiencing stress but lack psychological or resources to cope with the stressor, it is referred to the emotional resources as in this case is the friend support which may or may not provide the solution to the resources.

\subsection{Evaluation of Green Initiatives in Library's Facilities Based on Authors}

In achieving the first of objective of this study, second phase of the systematic review involved summarising green initiatives stated in three existing checklists by Noh and Ahn (2018), Werner (2013), and Mulford and Himmel (2010). In addition, the frequency of these initiatives being mentioned in those existing checklists were also evaluated and shown in table below. 


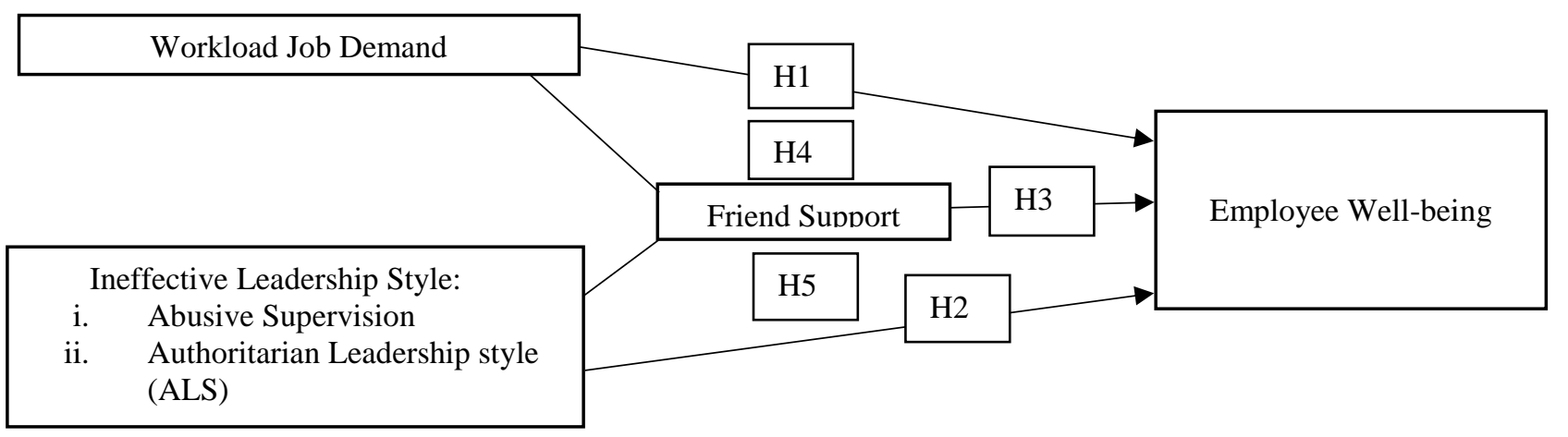

Source: (Nguyen \& Dinh, 2019; Craig \& Kuykendall, 2019; Nauman, Raja, Haq \& Bilal, 2019; Ahmad, Sohal \& Wolfram, 202; Pyc, Meltzer \& Liu, 2017)

Fig. 1 - Proposed conceptual framework

\section{Conclusion}

Employee well-being is considered to be one of the important key factors to sustain a business in a long-term focus in any organization. However, there are limited studies on contributing factors to the decrease of employee well-being such as workload job demand and ineffective leadership particularly in the oil and gas industry. Hence, this study is expected to further deepen the understanding on these issues and more importantly to add to the existing body of knowledge on this particular subject.

As for the proposed conceptual framework model, the results for the findings on the independent variable comprised of workload job demand and ineffective leadership (abusive leadership and ALS) as well as the dependent variable is the employee well-being (emotional exhaustion and job satisfaction) are expected to further fill the gaps in the literature. This study is also expected to gain new findings on friend support as mediating factor and results of this study will be reported in future publications.

\section{Acknowledgement}

The author would like to thank Universiti Teknologi MARA (Sabah) for supporting this research work.

\section{References}

[1] Ahmad, S., Sohal, A. S., \& Cox, J. W. (2019). Leading well is not enough A new insight from the ethical leadership, workplace bullying and employee well-being relationships. Ethical

[2] Bakker, A., Demerouti, E., De Boer, E., \& Schaufeli, W. (2003). Job demands and job resources as predictors of absence duration and frequency. Journal of Vocational Behavior, Vol. 62 No. 2, 341-356

[3] Craig, L., \& Kuykendall, L. (2019). Examining the role of friendship for employee well-being. Journal of Vocational Behavior 115

[4] Hartup, W. W., \& Stevens, N. (1997). Friendships and adaptation in the life course. Psychological Bulletin, 121,355

[5] Hobfoll, S. (1989). Conservation of resources: a new attempt at conceptualizing stress. American Psychologist, Vol. 44 No. 3, 513-524

[6] Karasek, R. (1979). Job demands, job decision latitude, and mental strain: Implications for job redesign. Administrative Science Quarterly, Vol. 24 No. 2, 285-308

[7] McCarthy, G., Almeida, S. \& Ahrens, J. (2011). Understanding employee well-being practices in Australian organizations. International Journal of Health, Wellness \& Society, 1 (1), 181-198

[8] Mika F., Dalida R., Kapanadze E. T., Visnjic-Pichler N., (2012). Stress and Social Anxiety Assessment among Offshore Personnel in Oil and Gas Industry. https://www.onepetro.org/conference-paper/SPE-156536-MS

[9] Nguyen, D. T. N., Teo, S. T. T., \& Dinh, K. C. (2019). Social support as buffer for workplace negative acts of professional public sector employees in Vietnam. Public Management Review, 00(00), 1-21. https://doi.org/10.1080/14719037.2019.1638438

[10] Nauman, S., Raja, U., Haq, I. U., \& Bilal, W. (2019). Job demand and employee well-being: A moderated mediation model of emotional intelligence and surface acting. Personnel Review

[11] Pyc, L. S., Meltzer, D. P., \& Liu, a. C. (2016). Ineffective Leadership and Employees' Negative Outcomes: The Mediating Effect of Anxiety and Depression. International Journal of Stress Management 
[12] Spector, P. E., \& Jex, S. M. (1998). Development of four self-report measures of job stressors and strain: Interpersonal Conflict at Work Scale, Organizational Constraints Scale, Quantitative Workload Inventory, and Physical Symptoms Inventory. Journal of Occupational Health Psychology, 3(4), 356-367 https://doi.org/10.1037/1076-8998.3.4.356

[13] Taylor C. (2018 August). combating-stress-in-workplace. Energy Voice. Retrieved from URL.https://www.energyvoice.com/other-news/180507/combating-stress-in-workplace/

[14] Tepper, B. J. (2000). Consequences of abusive supervision. Academy of Management Journal 43, $178-190$.

[15] Yukl, G. (2012). Effective leadership behavior: What we know and what questions need more attention. Academy of Management Perspectives, 26(4), 66-85

[16] He, G., An, R., \& Hewlin, P. F. (2019). Paternalistic leadership and employee well-being: a moderated mediation model. Chinese Management Studies, 13(3), 645-663. https://doi.org/10.1108/CMS-10-2018-0724

[17] Hobfoll, S. E. (1988). The ecology of stress. New York, NY: Taylor \& Francis

[18] Hobfoll, S. E., Freedy, J., Lane, C., \& Geller, P. (1990). Conservation of social resources: Social support resource theory. Journal of Social and Personal Relationships, 7, 465-478. https://doi.org/10.1177/0265407590074004

[19] Cooper CL, Sutherland VJ. (1987, Feb 29). Job stress, mental health, and accidents among offshore workers in the oil and gas extraction industries. J Occup Med. 1987 Feb;29(2):119-25. PMID: 3819891.

https://pubmed.ncbi.nlm.nih.gov/3819891/

[20] Thomas, A. (2018, August 31). Combating stress in workplace - News for the Oil and Gas Sector. Energy Voice. https://www.energyvoice.com/other-news/180507/combating-stress-in-workplace/

[21] PETRONAS MPM. (n.d.). www.Petronas.Com/Mpm. Retrieved July 7, 2020, from https://www.petronas.com/mpm/malaysia-oil-gas-landscape/current-investors

[22] EY. (2016). Global oil and gas transactions review 2015. Ernst \& Young Publications. Retrieved from http://www.ey.com/Publication/vwLUAssets/EY-global-oil-and-gas-transactions-review-2015/\$FILE/EYglobal-oil-and-gas-transactions-review-2015.pdf

[23] Tucker, C. J., Finkelhor, D., \& Turner, H. (2020). Family and friend social support as mediators of adolescent sibling victimization and mental health, self-esteem, and delinquency. American Journal of Orthopsychiatry, 90(6), 703-711. https://doi.org/10.1037/ort0000502

[24] Toni L. Bisconti, MA, C. S. Bergeman, PhD, Perceived Social Control as a Mediator of the Relationships Among Social Support, Psychological Weil-Being, and Perceived Health, The Gerontologist, Volume 39, Issue 1, February 1999, Pages 94-104, https://doi.org/10.1093/geront/39.1.94

[25] Employee wellbeing - the bigger picture. (2017, June 27). The Telegraph https://www.telegraph.co.uk/business/business-reporter/employee-wellbeing-bigger-picture/

[26] Quantitative Workload Inventory QWI. (2020, September 7). Paul Spector. http://paulspector.com/scales/pauls-no-cost-assessments/quantitative-workload-inventory-qwi/

[27] Cheng, B.S., Chou, L.F., Wu, T.Y., Huang, M.P. and Farh, J.L. (2004), "Paternalistic leadership and subordinate responses: establishing a leadership model in Chinese organizations", Asian Journal of Social Psychology, Vol. 7 No. 1, pp. 89-117

[28] Procidano, M. E., \& Heller, K. (1983). Measures of perceived social support from friends and from family: Three validation studies. American Journal of Community Psychology, 11, 1-24. https://doi.org/10.1007/BF00898416

[29] Pines, A. and Aronson, E. (1988), Career Burnout: Causes and Cures, Free press, New York, NY.

[30] Judge, T. A., Locke, E. A., Durham, C. C., \& Kluger, A. N. (1998). Dispositional effects on job and life satisfaction: The role of core evaluations. Journal of Applied Psychology, 83(1), 17-34. https://doi.org/10.1037/0021-9010.83.1.17

[31] Brayfield, A. H., \& Rothe, H. F. (1951). An index of job satisfaction. Journal of Applied Psychology, 35(5), 307-311

[32] House, J. S. (1981). Work stress and social support. Reading. MA: Addison-Wesley

[33] Schaufeli, W.B. and Bakker, A.B. (2004a), "Job demands, job resources, and their relationship with burnout and engagement: a multi - sample study” , Journal of Organizational Behavior: The International Journal of Industrial, Occupational and Organizational Psychology and Behavior, Vol. 25 No. 3, pp. 293-315

[34] Enzmann, D., Schaufeli, W.B., Janssen, P. and Rozeman, A. (1998), Dimensionality and validity of the Burnout Measure. Journal of Occupational and Organizational Psychology, 71: 331351. https://doi.org/10.1111/j.2044-8325.1998.tb00680.x 